\title{
Accessibility to the drinking water sources in Burkina Faso: the case study of Toessin and Bonogo villages
}

\author{
Nabaloum Moumouni ${ }^{1}$, Ouoba Awa Pounyala ${ }^{1}$, Da Evariste Constant Dapola ${ }^{1}$ \\ ${ }^{1}$ Department of Geography, Training and Research Unit in Human Sciences, \\ University of Ouagadougou
}

Correspondence: Nabaloum Moumouni (email: mouninabaloum@gmail.com)

Received: 28 November 2019; Accepted: 05 February 2020; Published: 30 May 2020

\begin{abstract}
In Africa, accessibility to drinking water is major problem for rural population. This study analyzes accessibility to the drinking water source in two villages in Burkina Faso. Data were obtained from household's surveys. In total, 221 households have been surveyed. Data analysis method is based on water accessibility of World Health Organization \& United Nations Children Fund (2017) and Howard \& Bartram (2003) approach. Results show that in Toessin village, more than half of the households have improved service or intermediate access to wells, whereas a small percentage have access to boreholes. Slightly over half of the households have a low service or a minimal access for the same quantities of water and sources. No household falls under the limited service state or does not have access to wells, whereas small number of the families do not have access to boreholes. In the Bonogo village, nearly one third of households have improved service or intermediate access to boreholes and a very small number of household have intermediate access to wells. The majority of the Bonogo household's access to boreholes fall under the basic service or a minimal access category, whereas accessibility to wells under the same category constitute slightly over half of the household. However, only a very small number of household in Bonogo have a limited service or do not have access at boreholes and wells. Overall, in terms of accessibility to drinking water sources, the majority of households in Toessin falls under the improved service or intermediate/minimal access for wells, whilst in Bonogo, most households fall under the basic service or minimal access to boreholes. It is necessary to dig new boreholes in Toessin in order to improve access to the drinking water.
\end{abstract}

Keywords: accessibility, boreholes, Burkina Faso, drinking water, households, traditional wells

\section{Introduction}

The adage, "the water is life and without it, there is no life", indicates the importance of water in life. The availability of the water and its management constitute one of the challenges of the 21 st century because it must satisfy the needs of a world population in strong growth. About 663 million people, living in rural areas, did not have access to an improved drinking 
water source in 2015 (UNICEF, 2016). In sub-Saharan Africa, particularly, 80\% of the population in rural zones did not have access to adequate drinking water. Among the explanatory factors, there are the environmental conditions. Besides, in Sahelian regions, the water problems pose with more acuteness than Soudanian climate regions because of an insufficient and irregular rainfall (Richardson, 2017). In these Sahelian regions, the precocious drying up of water points during the dry season cause populations displacements. According Richardson, the quantity of water available for the population in a region was therefore dependent on regional hydrology and hydrogeology. Natural factors are not only the cause of the disparities observed in the space related to access to the water because, for geographer David Blanchon, it is mainly the incapability to mobilize this resource and put it available to the populations according to their needs that determines the problems related to water (Chevallier-Le-Guyader, 2012). The social strain that exists around the water points are due to the unavailability of the hydraulic infrastructures, the state of their functioning and the nature of the management mode (Baron \& Bonnassieu, 2011; Karuaihe et al., 2014).

In Burkina Faso, one third of the population did not get access to drinking water in 2017 compared to $20 \%$ on average in the developing countries. The reasons, according to Traoré (2012), were related to the internal and hierarchical organization of the village space. Indeed, according to this author, in the river of Nakambé zone, the origin of the residents influenced the access of water points. Thus, the land management was founded on the antecedence of the presence. The natives detained the control of the social phenomena that contributed to enhance spaces. The appropriation of the land was perceived as a cultural phenomenon and if water came from of soil, the considerations that every actor makes himself of water result of the same cultural system. The no landholder and migrants were submitted to the requirements of the owners of water points. The antecedence was indispensable and legitimate the power around the water management. It is a manner of exclusion of the migrants and the influence of the natives on the one hand on the land management and on the other hand on the one of water. On this basis, the migrants saw their access to water constrained and restricted because they did not have any right on the land. These same societal characteristics existed in the Sahel and savanna regions of Burkina Faso (Baron \& Bonnassieu, 2011). The rate of access in drinking water in Burkina Faso was $12.49 \%$ (Béré, 2012). The reasons mentioned to explain this low rate were also the precocious drying up of wells in dry season and the distance to the water points.

The collection of drinking water stays however a major burden in Africa. For example, in Sub-Saharan Africa many people spend more than 30 minutes or more than one hour on water-seeking. This task is mainly incumbent upon women and girls. In Africa, it is estimated $70 \%$ of the women concerned involves in the collection of water. In Rwanda, by example, they travelled more than 3 kilometers to collect water (Koolwal \& Van de Walle, 2013). It is why, to reduce this distance, the first step of the objective 6 of the United Nations Sustainable Development Goals aims to provide every citizen a basic service and access to water within 30 minutes.

Access to water is a polysemic notion. It is defined sometimes in terms of distance and quantity of water available by day and per person. Sometimes access to water is defined as "the availability of a source of water supply within 30 minutes" (INSD, 2009). The national policy of Burkina Faso distinguishes access to water in rural zone and the one of urban zone (Ousseini, 2010). However, studies conducted by the United Nations in 24 countries in the Sub-Saharan Africa indicates that approximately 3.36 million children and 13.54 million adult women are concerned when the water collection time exceeded more than 30 minutes (UNICEF Media Team, 2016).

Access time to the source of water remains, therefore, a major challenge for the social and economic development of women and girls. In Tanzania, for example, the reducing water 
collection time from 30 minutes to 15 minutes, would increase the girls' school attendance by $12 \%$. Improved access to safe drinking water would allow women to spend hundreds of hours with their families, as well as the "possibility to earn their living" (Mahmood, 2016). In Ethiopia, the same condition exist, women and girls spent 3-4 hours per day for fetching drinking water. This situation implied the student will miss 37-51 days from the total learning period per year and it is estimated about $54.8 \%$ of young daughters were not enrolled for the education. 'Collecting water' was the first reason explains the non-enrollment of these young girls in school (Demie et al., 2016). Reduction in the water collection time and the increase of the number of people having water sources no furthest of their dwelling are essential to achieving the goals of poverty alleviation, goals of struggle against poverty, access to health, assurance of education and the equality between the sexes (Slaymaker \& Bain, 2017).

Many indicators on the water availability have been described (spatial coverage rate, coverage rate relative to population, distance from dwellings to water source, water price) to identify the needs of the populations. The description of these indicators suggests that "the physical availability of the water" is the common point between them (Richardson, 2017).

In Burkina Faso, studies have generally focused on issues of problems resolution related to drinking water supply and management of water resource (Traoré, 2012: Laurence, 2004: Program GIRE, 2001; M'body, 2009; Program Water and Cleaning up, 2011; Béré, 2012; Dos Santos, 2006). Few research focused on access conditions to drinking water sources. Therefore, there is a need to analyse the conditions that determine the frequentation of the drinking water sources others that those imposed by the factors of the natural environment. The main objective of this study is to examine accessibility and the conditions of access to the sources of drinking water sources in two villages in Burkina Faso.

\section{Study area and method}

\section{Study areas}

Toessin village is located at $12^{\circ} 44^{\prime} 27^{\prime \prime}$ West longitude and $2^{\circ} 23^{\prime} 30^{\prime \prime}$ North latitude. It is situated in the department of Samba, 35 kilometers to the south of Yako town. Whereas, Bonogo village is located at $12^{\circ} 09^{\prime} 59^{\prime \prime}$ West longitude and $1^{\circ} 37^{\prime} 36^{\prime \prime}$ North latitude. Toessin village located within the Samba department of the Passore province under the Nord region Bonogo located within the Saponé department of the Bazega province under the South-center region As showed in Figure 1, these two villages belong to the Soudano-Sahelian climate with nearly the same length of the rainy and dry season. Figure 2 and Figure 3 indicate that the climate of Toessin and Bonogo is characterized by a dry season from October to May, and a rainy season from June to September. According to data of the National Meteorology Agency of Burkina Faso, the average annual rainfall between 1986 and 2015 is $707.2 \mathrm{~mm}$ per year for Toessin and $745 \mathrm{~mm}$ per year for Bonogo. These seasonal and monthly variations have some impacts on the level of the groundwater and consequently on the availability and the access to the drinking water. 


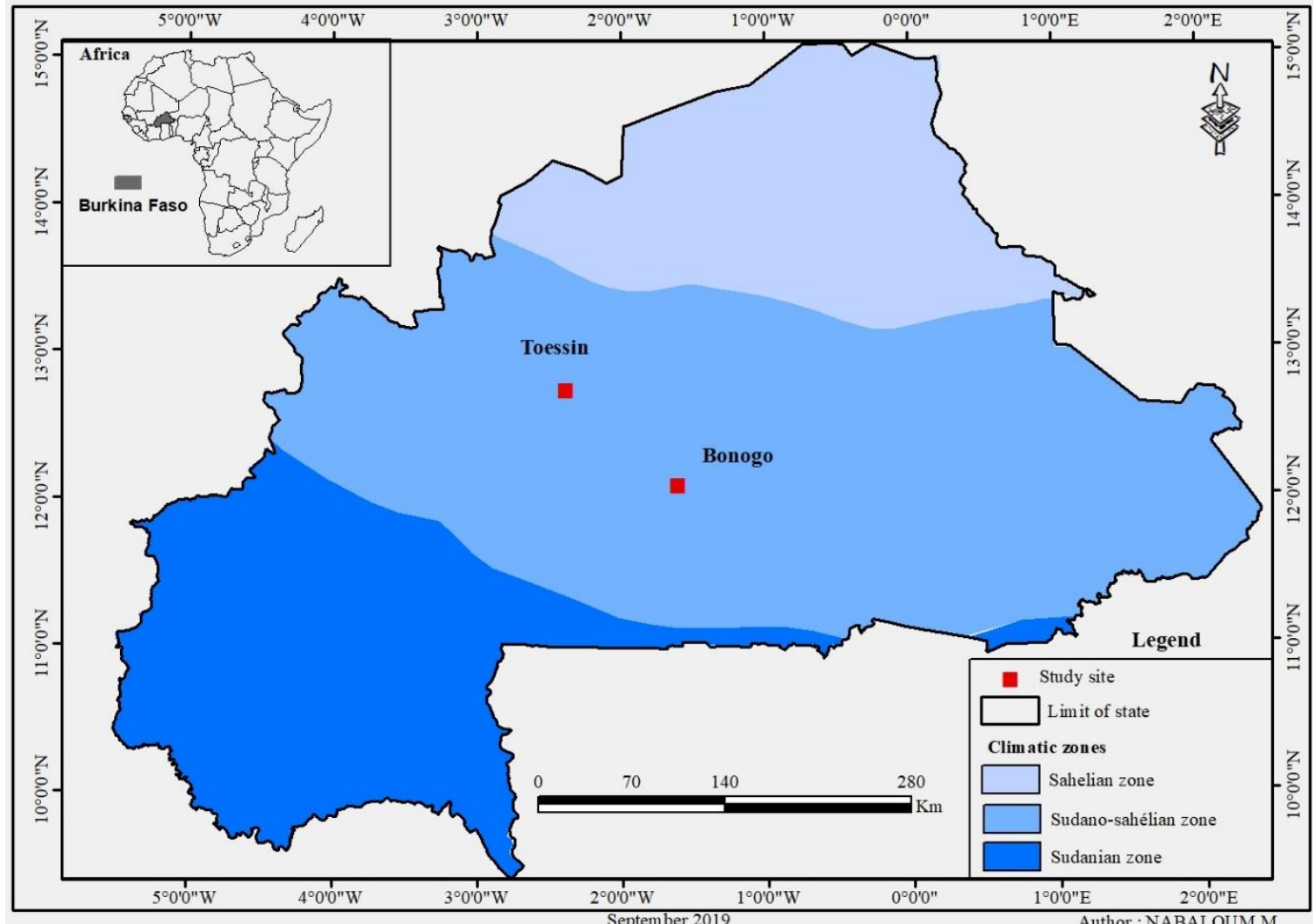

Source: Institute Geographical of Burkina Faso and National Meteorology Agency

Figure 1. Location of study sites

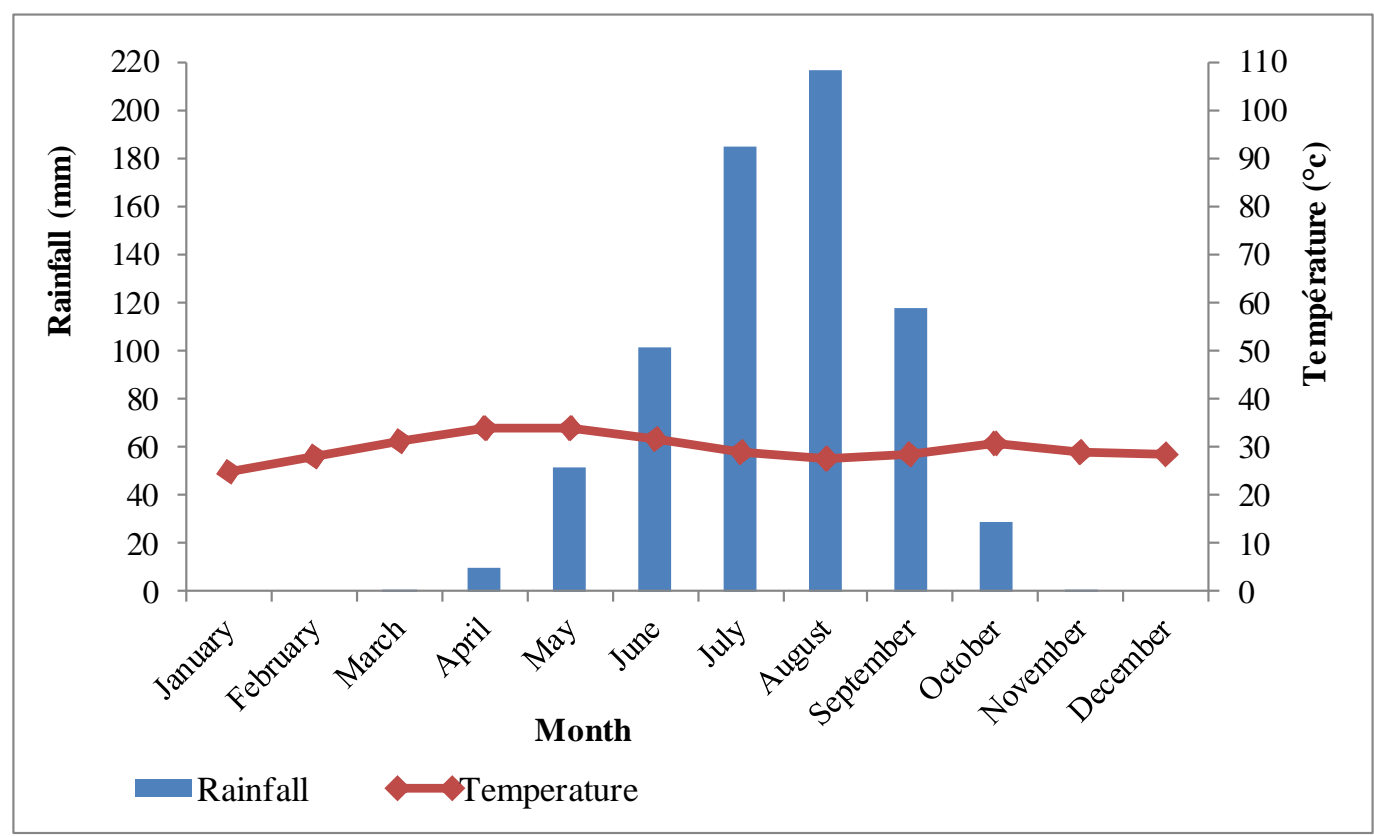

Source : National Meteorology Agency

Figure 2. Ombrothermic diagram of the Yako station (1986-2015) 


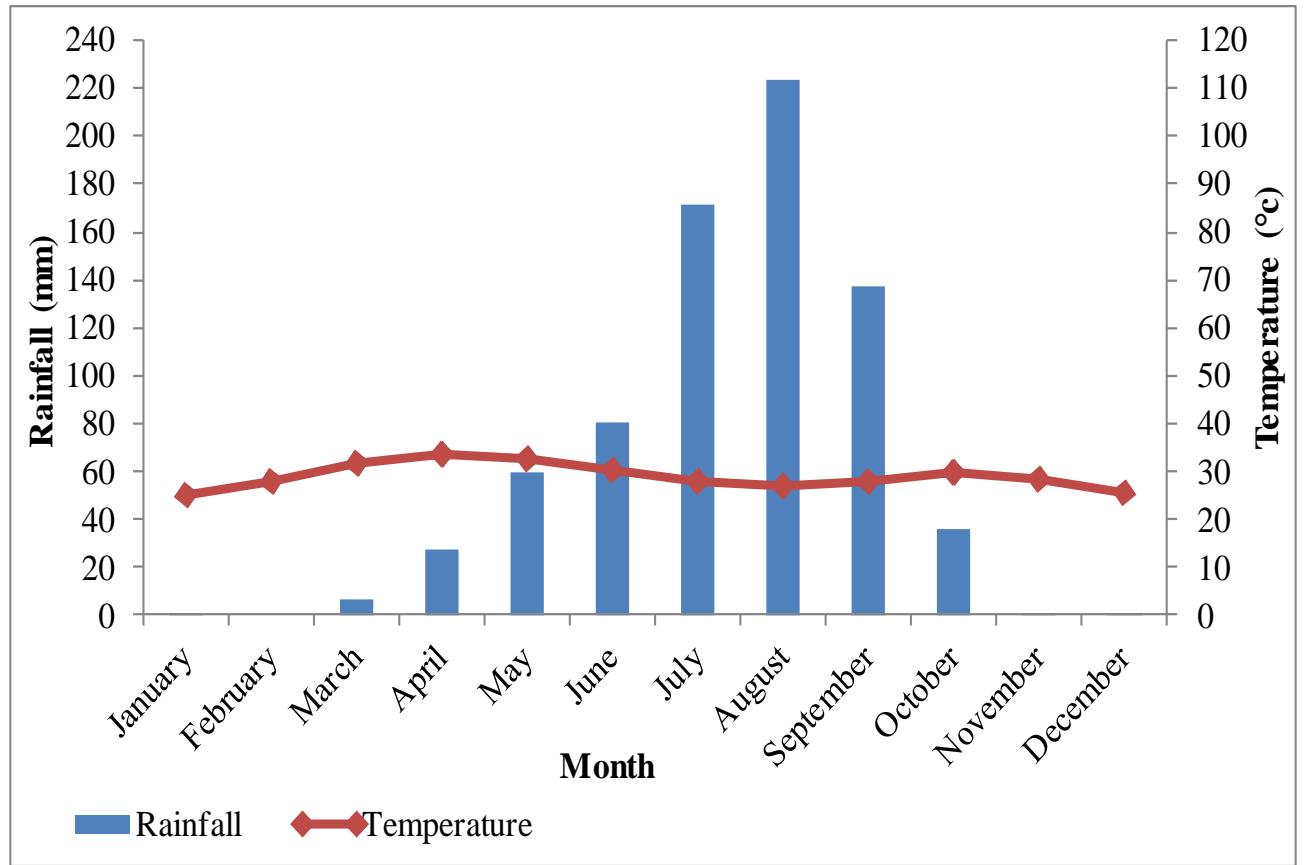

Source : National Meteorology Agency

Figure 3. Ombrothermic diagram of the Saponé station (1986-2015)

A major part of Toessin is located on a plane surface with an altitude of 300 meters and localized on a low glacis of a hill of altitude 700 meters. The soils are essentially ferruginous and leached. According to Zoungrana (2013), there are two types of rock, the crystalline rocks and metamorphic rocks, which formed the geological base of the Toessin region. The crystalline rocks are composed mainly of syntectonic acidic rocks that include biocatalytic alkalic granites. These rocks appear in the central part of the village of Toessin. The metamorphic rocks include birrimian rocks of parametamorphic origin composed of schists and quartzites.

Bonogo village is located on a plain with an average altitude of 300 meters. The soils are hydromorphic, ferruginous and gravelly. The geological formations of Sapone, included Bonogo, consist of crystalline formations including granites, magmatic, gneiss and shales. These materials are characterized by their low permeability (Ouadba, 2003).

The population of Toessin was estimated at 3220 inhabitants in 2005 and 3859 inhabitants in 2015, with an average growth rate of $2 \%$ per year. Bonogo village have 268 households in 2013. The total population was estimated at 1622 inhabitants in 2006 against 2220 inhabitants in 2016 with a yearly growth rate of 3.7\%. These demographic growths must be followed by digging of others hydraulic infrastructures in particular boreholes or common pipe bornes water in order to satisfy the needs in drinking water for populations.

The hydrographic system of the village of Toessin and its department (Samba) belong largely to the Nakambé river basin. This hydrographic is constituted by tributary and of under tributary of the Nakambé. They dry up at the end of winter season. There is no permanent river. Nevertheless, some depressions form temporary reservoirs of water after rains. The hydrographic system of Bonogo region is located between two river basins, the basin of the Nakambé to the north and the one of Nazinon to the south. Their main tributaries are Kalaté, Bissiga and Narialé. Surface and groundwater of these two localities are replenished by the rainfall. However, a decrease in the rainfall amount entails consequences of an early drying up of rivers and wells. 


\section{Materials and Method}

This study utilized both primary and secondary data. Data were collected during the first quarter of 2016. Climatic data (temperatures, rainfalls) were collected from National Meteorology Agency of Burkina Faso. Topography, geology and soils data were provided by National Institute of Geography. Demography information were given by sanitary districts of these localities.

The quantitative and qualitative approaches were used. The information gathered concerned the types of drinking water sources, the number of sources, the time taken to reach sources, the drying of water sources and the daily quantity of water collected (in number of 20-liter cans) were recorded through a questionnaire survey. The time taken to reach from residents' house to water source was measured using a time watch. Thus, the survey unit was the household and the respondent is the chief of household (man or woman). In total, 221 households were surveyed including 120 in Toessin and 101 in Bonogo.

Data processing was done on Microsoft Excel 10 software and exported to Statistical Package for Social Sciences (SPSS) version 21. SPSS was used to assess the relationship between variables (access to traditional wells/boreholes, number of traditional wells/boreholes, time access to wells/boreholes, household size and quantities of water collected) by the method of Pearson correlation (r). This coefficient of correlation between two variables $\mathrm{X}$ and $\mathrm{Y}$ takes values situated between -1 and +1 . According to Cusson et al. (2010), a "-1" correlation represents a perfect negative linear relationship (variables are related by a relationship perfectly inversely proportional); a "0" correlation indicates a total absence of relationship between variables; whereas a " $+1 "$ correlation represents a perfect positive linear relationship (variables are related by a linear relationship perfectly directly proportional). Between these two values, the correlation coefficient indicates that variables are more or less linked between them.

To analyze the accessibility to drinking water, we opted for the drinking water accessibility approach of the World Health Organization (WHO) \& United Nations Children Fund (UNICEF) (2017) and Howard and Bartram (2003). WHO \& UNICEF (2017) and Howard and Batram (2003) have defined three levels of drinking water service, taking into account the time taken to reach the source (Table 1). So the source of water is considered in state of improved, basic and limited service or the populations are judged do not access, have a minimal or intermediate access at the source of water if this source is situated more or less to one long time of walk.

Table 1. Service level for accessibility to drinking water

\begin{tabular}{|c|c|}
\hline Service level & Distance/time \\
\hline \multicolumn{2}{|l|}{ WHO/UNICEF (2017) } \\
\hline Improved service & 0 minutes from the point of use \\
\hline Basic service & between 1 minute and 30 minutes \\
\hline Limited service & beyond 30 minutes \\
\hline \multicolumn{2}{|l|}{ Howard \& Bartram (2003) } \\
\hline No access & 1 kilometer or more than 30 minutes \\
\hline Minimal access & $\begin{array}{l}\text { between } 1 \text { kilometer and } 100 \text { meters or less than } \\
30 \text { minutes }\end{array}$ \\
\hline Intermediate access & within 100 meters or 5 minutes \\
\hline
\end{tabular}




\section{Results and discussion}

\section{Social characteristics of respondents}

The respondents were composed of $88 \%$ and $82 \%$ of men in Toessin and Bonogo, $12 \%$ and $18 \%$ were women respectively. The majority of the household's members interviewed was men. The low proportion of the women is due to their occupation and sometimes she left their homes very early in the morning. In terms of religion, $14 \%$ and $3 \%$ were animists, $15 \%$ and $86 \%$ of Christians, $71 \%$ and $11 \%$ were Moslem respectively in Toessin and Bonogo (Table 2).

The average household size of respondents in Toessin was 5 and 7 for Bonogo. The household size varied between 3 and 18 persons in Bonogo, and up to 33 persons in Toessin. About $62 \%$ and $76 \%$ of households had $3-9$ persons, whereas $22 \%$ and $18 \%$ of families had 10-14 persons in Toessin and Bonogo respectively (Table 3). Households in Toessin have a larger family size in relation to Bonogo. The size of a household determined the quantity of water consume, large family has higher demand for water than smaller family (Ifabiyi et al., 2019).

Table 2. Social profiles of respondents in the study sites

\begin{tabular}{cccccc}
\hline Sites & Men (\%) & Women (\%) & Animist (\%) & Christians (\%) & Moslem (\%) \\
\hline Toessin & 88 & 12 & 14 & 15 & 71 \\
Bonogo & 82 & 18 & 3 & 86 & 11 \\
\hline Source: Field survey & & & &
\end{tabular}

Table 3. Household size of respondents in the study sites

\begin{tabular}{cccccc}
\hline Sites & $\mathbf{3 - 9}$ & $\mathbf{1 0 - 1 4}$ & $\mathbf{1 5 - 1 9}$ & $\mathbf{2 0 - 2 4}$ & $\mathbf{2 8 - 3 3}$ \\
\hline Toessin & 62 & 22 & 9 & 5 & 2 \\
Bonogo & 76 & 18 & 6 & 0 & 0 \\
\hline Source: Field survey & & &
\end{tabular}

\section{Main sources of drinking water}

Results show from surveys analyses that the sources drinking water in Toessin and Bonogo are mainly traditional wells and boreholes. Figures 4 and 5 show the type of drinking water source in study area.

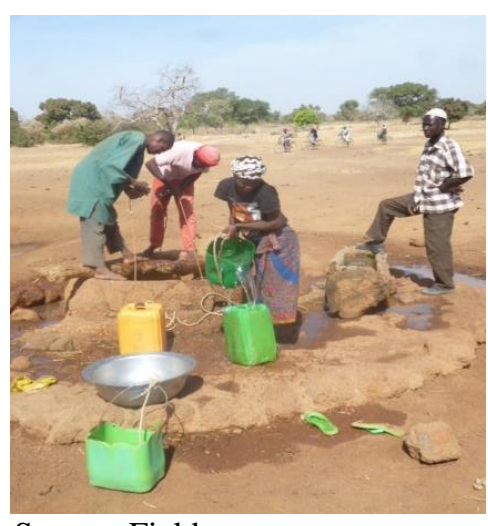

Source: Field survey

Figure 4. A traditional unprotected well in Toessin.

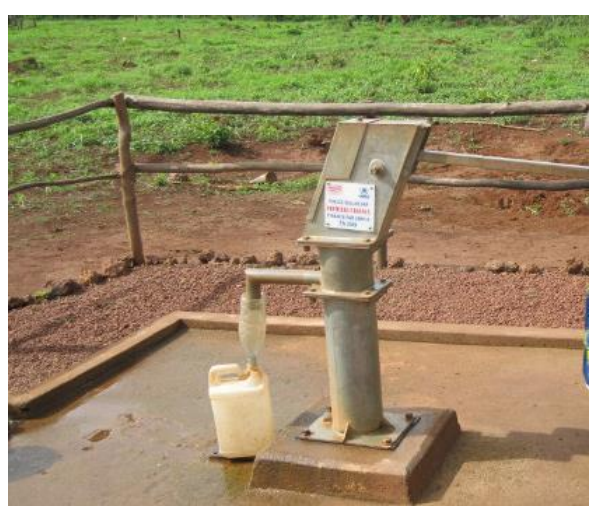

Source: Field survey

Figure 5. A borehole in Bonogo. 
Households go more or less to these water sources. The surveys revealed that in Toessin, households collect water in four traditional wells and two boreholes. In fact, $25 \%$ of the surveyed households only collect the water in the wells when $1 \%$ of households go exclusively to the boreholes (Figure 6). These results indicate these families have wells in their concessions and boreholes are furthers. Overall about $44 \%$ of them draw their drinking water from 1 well and 1 borehole, $15 \%$ from 2 wells and 1 borehole, $7.5 \%$ from 1 well and 2 boreholes, $2.5 \%$ from 3 wells and 1 borehole and $0.8 \%$ from 4 wells and 1 borehole (Figure 6). The relationship indicated that access to traditional wells is correlated significantly to the number of wells at $r=0.250$ degree. Access to boreholes and number of boreholes are fairly strong correlated at $r=-0.833$ degree. This suggests that as access to boreholes depend on number of boreholes and vice versa. That can be explain by the proximity and the numbers of wells in the village. However, Dione (2014), has notified that the number of traditional wells digging in rural zone in Senegal explained by the history of the water problems. The multiplication of the traditional wells enabled the populations to benefit from a water whose quality was better in relation to the surface water.

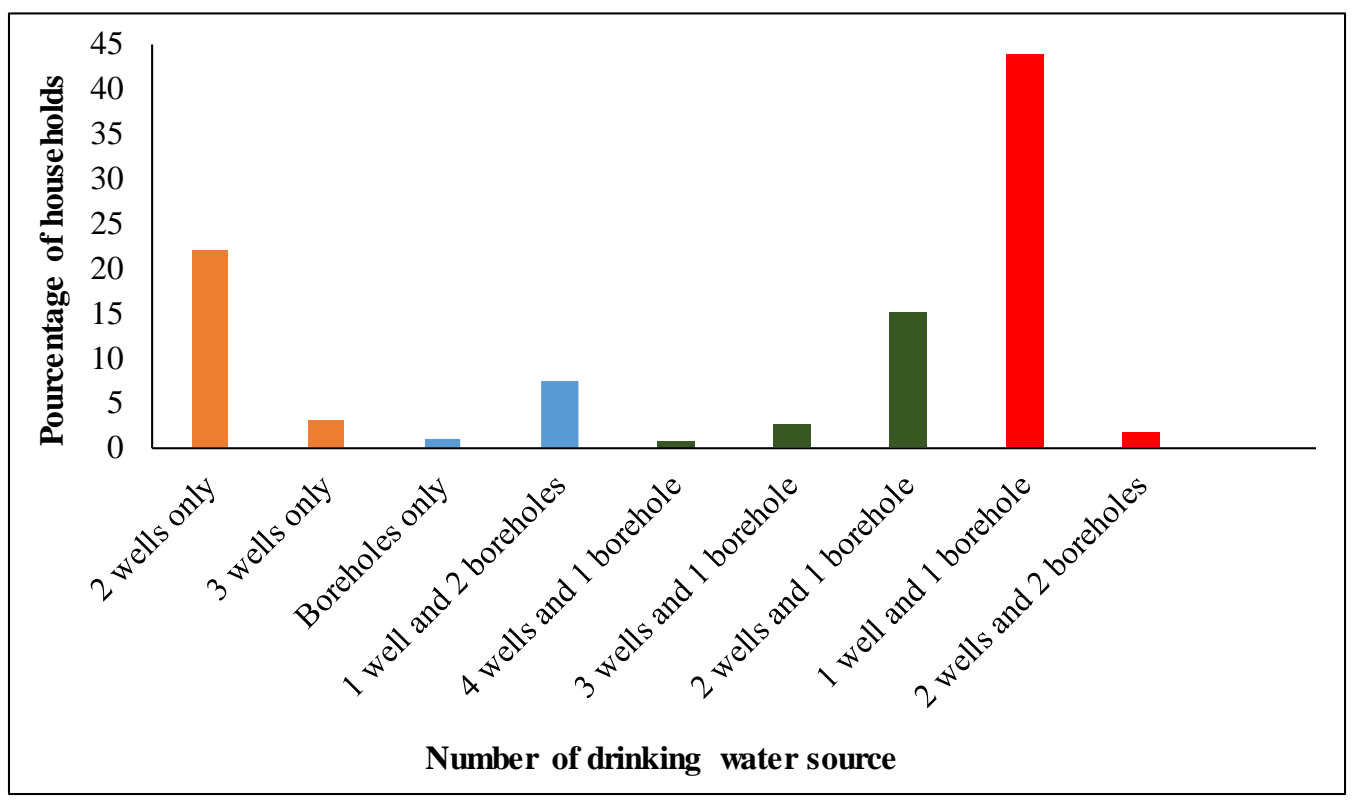

Source: Field survey

Figure 6. Number and type of drinking water source according to households in Toessin

While in Bonogo, inquired households seek the drinking water in three boreholes and two traditional wells. About $26 \%$ of the surveyed families only go to boreholes (Figure 7). Meanwhile 52\% of respondents collect the water in 1 well and 1 borehole, $18 \%$ in 1 well and 2 boreholes and 3\% in 1 well and 3 boreholes (Figure 7). Likewise, access to boreholes is correlated at $r=0.235$ degree with number of boreholes. Whereas, access to traditional wells and number of wells is fairly strong related at $r=0.976$ degree. These data are due in fact some households prefer to drink water in boreholes and others have not closest wells. Our results rejoice those of INSD (2009) which found 44\% of household drinking water comes from boreholes and 16\% comes from wells in Burkina Faso. In Benin, 53\% of women went to boreholes compared to 33.3\% for traditional wells (Houeha, 2007). The results presented by these two authors indicates that boreholes stay as the preferred source of drinking water for majority of the households in particular in Africa. 


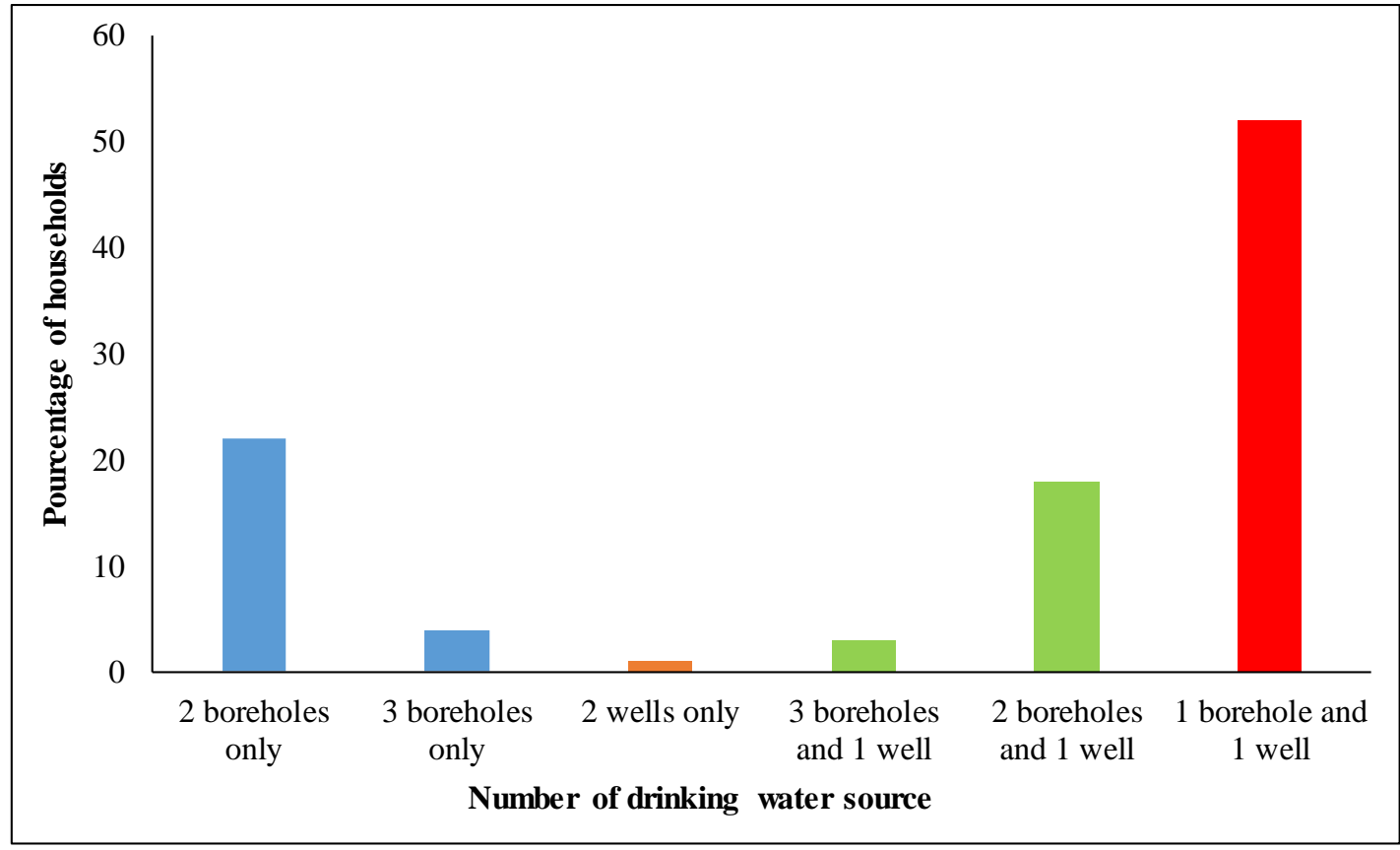

Source: Field survey

Figure 7. Number of drinking water source according to households in Bonogo

\section{Accessibility to drinking water sources}

In Toessin village, the surveyed households draw more drinking water from traditional wells than boreholes. In relation to the time taken to reach each water source, it appears that $66 \%$ of households have improved service or intermediate access respectively for traditional wells and $18.5 \%$ for boreholes. As shown in Figure 8, about 31\%, 18\% and $17 \%$ of the families arrive at a maximum of 5 minutes at the wells and collect respectively between 5 and 10 cans, 15 and 20 cans, 20 and 25 cans of 20 liters of water per day. This time allows $11 \%, 4 \%$ and $3.5 \%$ of households to reach boreholes near of the concessions and to draw the same quantities of water (Figure 9). Elsewhere, $57 \%$ and $41 \%$ of households have also low services or minimum access respectively for wells and boreholes. Indeed, 25\%, $18 \%$ and $14 \%$ of households take between 5 and 30 minutes to arrive at other wells and collect respectively between 5 and 10 cans, 15 and 20 cans, 20 and 25 cans of 20 liters of water daily (Figure 8). This time also allows $8 \%, 14,5 \%$ and 18, 5\% of the families surveyed to travel the distance from their dwelling to the boreholes and to draw the same quantities of water (Figure 9). However, no household is in a state of limited service or has no access to traditional wells while for boreholes $7 \%$ of families are in this situation. They have to go beyond of 30 minutes to collect water at the boreholes. The time access to boreholes is correlated at $\mathrm{r}=0.324$ degree with number of boreholes. Whereas the coefficient of correlation between time access to wells and number of wells is $r=0.302$ degree. These two values show that the relationships are significant between variables. 


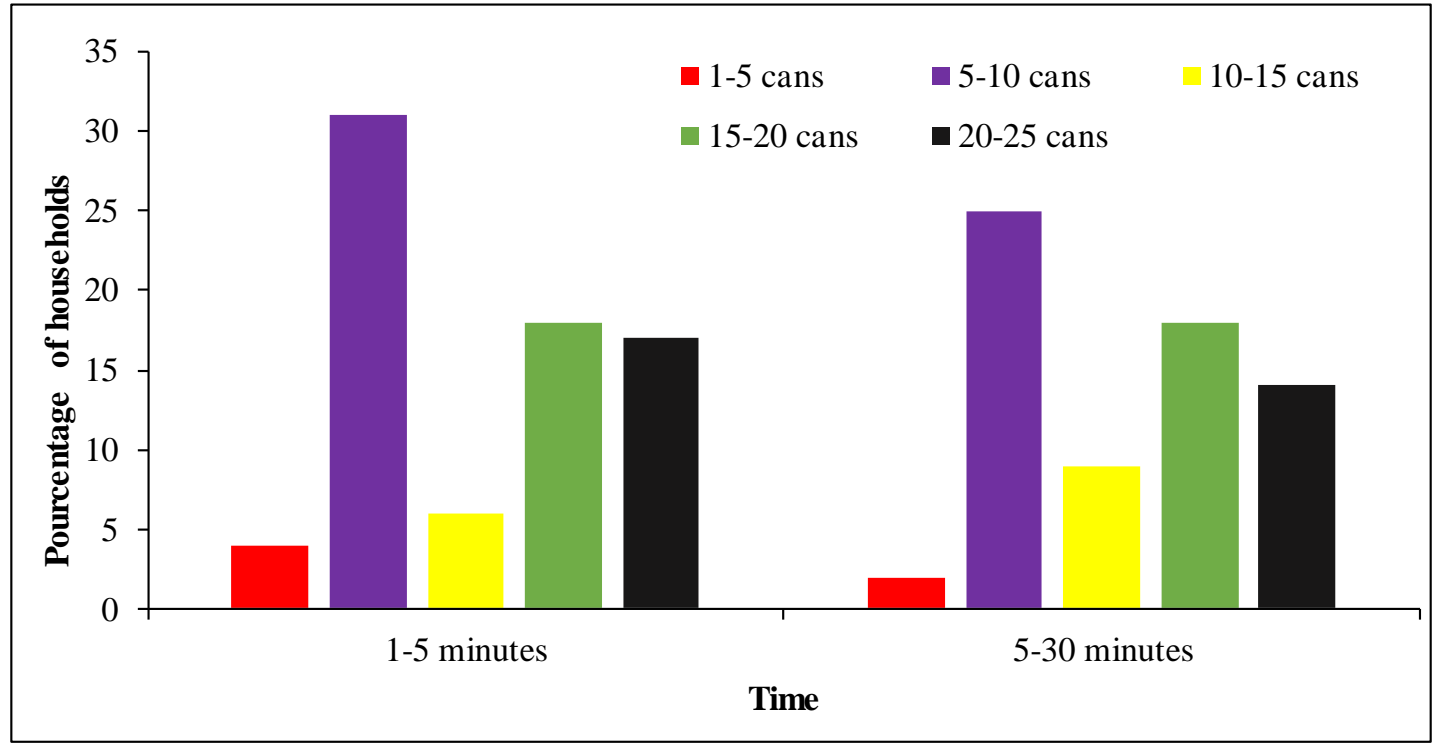

Source: Field survey

Figure 8. Access time to traditional wells and quantities of water collected by households in Toessin

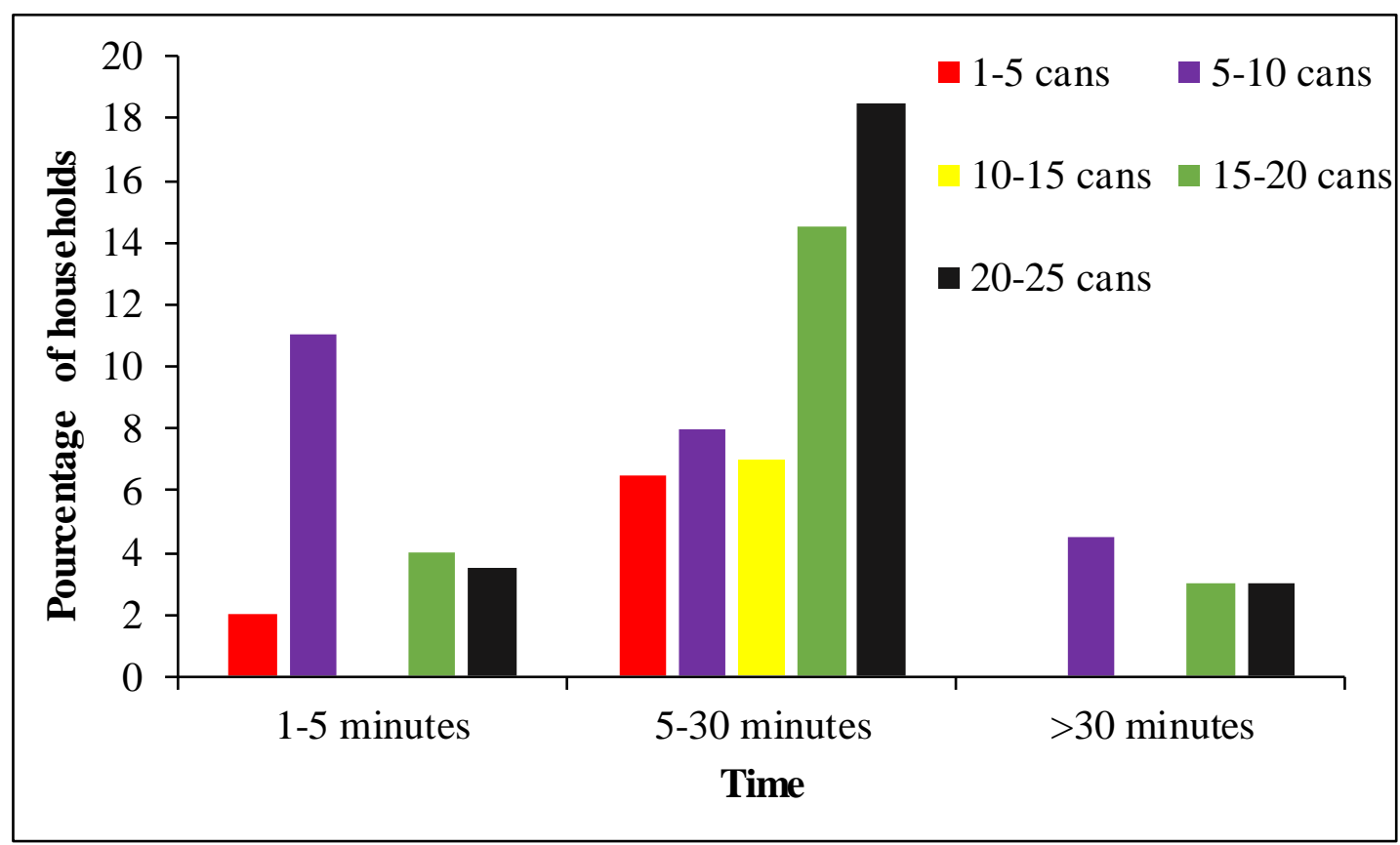

Source: Field survey

Figure 9. Access time to boreholes and quantities of water collected by households in Toessin

In contrast to Toessin village, the results from Bonogo survey show that households go much more to boreholes than to traditional wells. Overall, $22 \%$ and $4 \%$ of households have improved service or intermediate access to boreholes and traditional wells respectively. Indeed, $6 \%, 13 \%$ and $3 \%$ of the households spend at most 5 minutes to reach the boreholes to collect respectively 1-5 cans, 5-10 cans and 15-20 cans of 20 liters of water by day (Figure 10). Only $1 \%, 3 \%$ of households take at most 5 minutes to reach wells to collect 1 to 5 cans and 5 to 10 cans of water (Figure 11). All surveyed households have low service or minimum access to boreholes, while $53 \%$ of them are for traditional wells. Besides, $15 \%, 68 \%$ and $17 \%$ of families travel between 5 and 30 minutes to arrive in boreholes while 6\%, 37\%, 7\% and 
$3 \%$ of them spend the same time to rejoin the wells and collected the similar quantities of water (figures 10 and 11).

On the other hand, $2 \%$ and $12 \%$ of families have a limited service or no access to boreholes and traditional wells because they must travel beyond of the 30 minutes. Only $2 \%$ of the surveyed households go to boreholes for $1-5$ cans of water when $2 \%, 7 \%$ and $3 \%$ of them do it for traditional wells to collect 1-5 cans, 5-10 cans and 15-20 cans daily (Figures 10 and 11). In this case, time access to wells is correlated significantly at $r=0.329$ degree with number of wells.

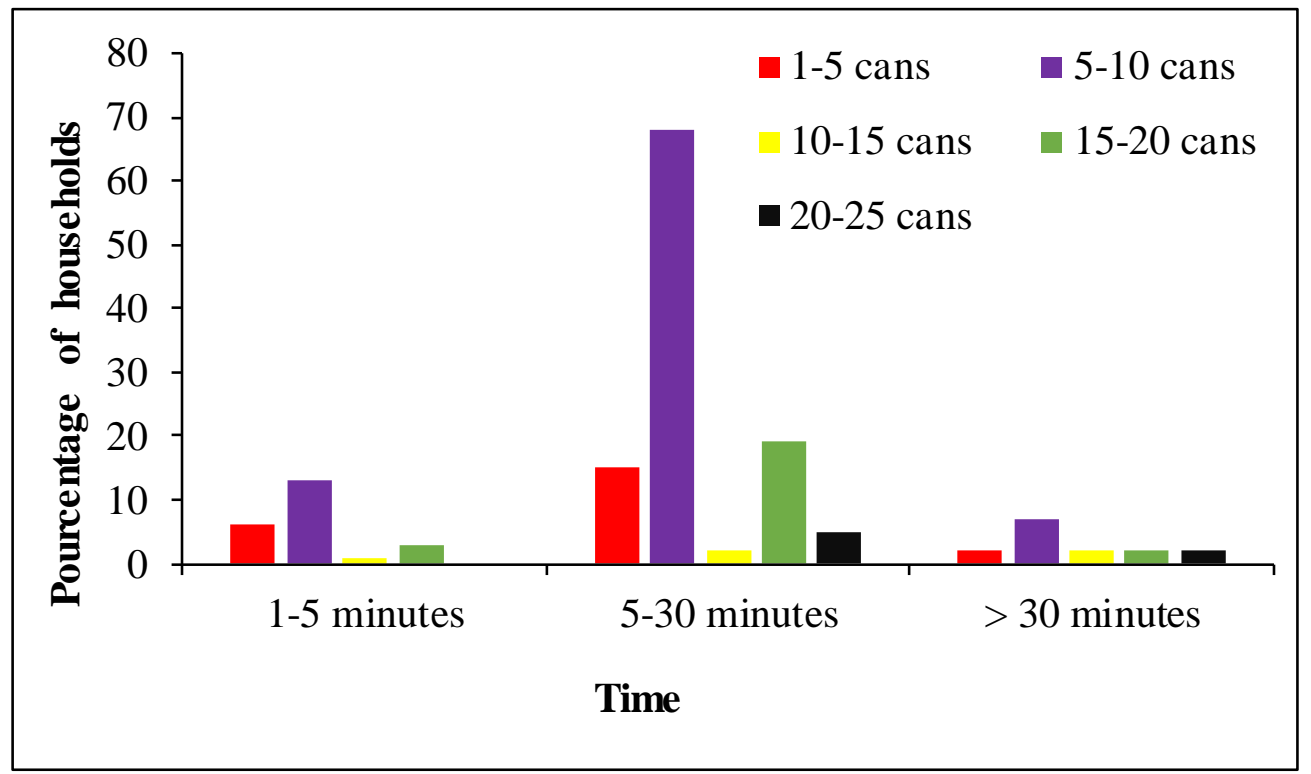

Source: Field survey

Figure 10. Access time to boreholes and quantities of water collected by households in Bonogo

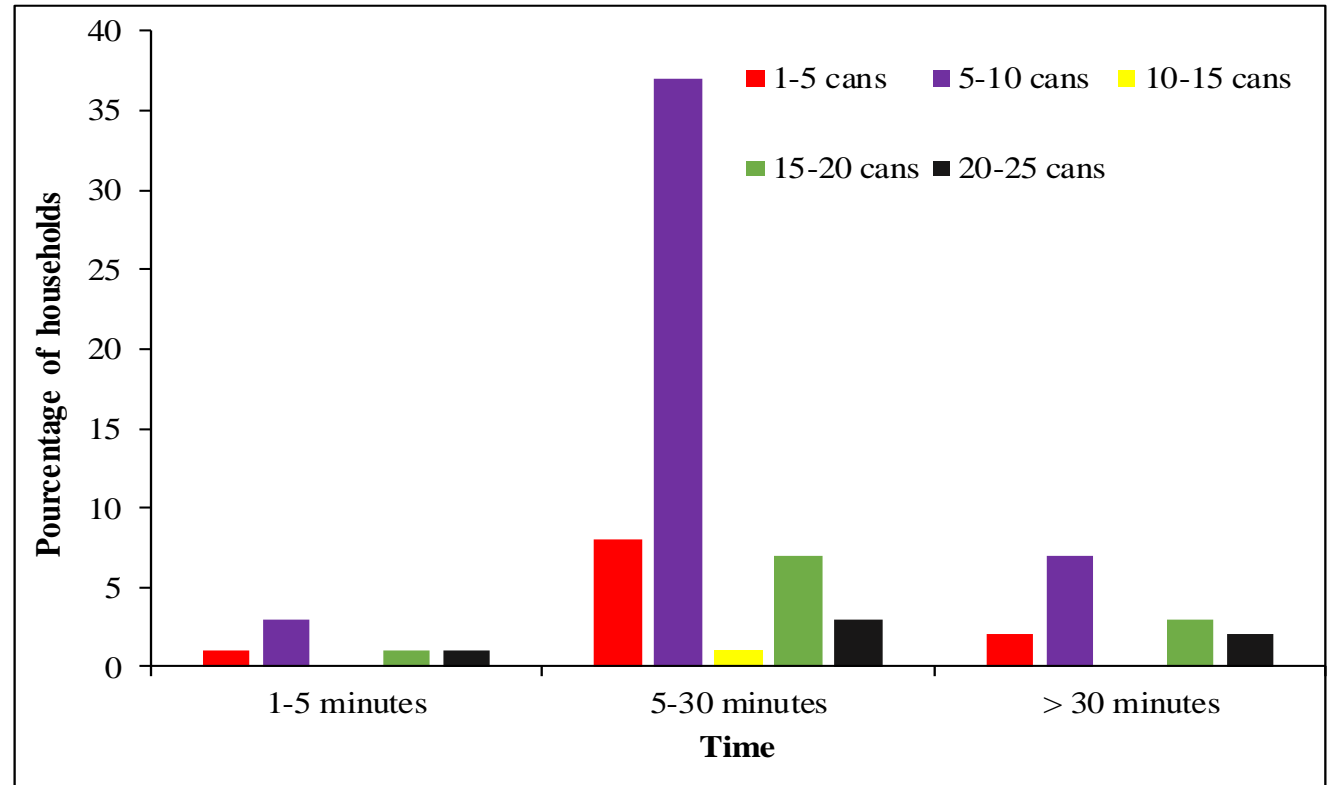

Source: Field survey

Figure 11. Access time to traditional wells and quantities of water collected by households in Bonogo 
In Toessin, collecting of the drinking water constitutes a suffering for some households because of the long distances to water sources, it would explain by the geomorphology of this site that is located on a low glacis. According to Akoteyon (2016), topography influences level of groundwater. It is very low for high topography zones. Consequently, there are high cost of drilling or digging to access groundwater.

Moreover, the growth of the population in the last decade, is not followed by digging of new boreholes in Toessin. According to the populations, the existing boreholes have been dug 15 or 20 years ago. The consequences of this situation is the polarization around the existing points of water and long distance to travel for reach other boreholes.

The accessibility of traditional wells compared to boreholes in Toessin can be explained on the one hand by the fact that some wells are sometimes dug inside the concessions and, on the other hand, 39\% of households have noticed that there is continual water in their well during the year. The choice to go to boreholes is due to the fact that $30 \%$ of households has also noticed an annual drying of their wells. Beyond topography, rainfall explains that because Olanrewaju et al. (2019) estimated that rainfall renews groundwater level and constituted a renewable resource in space and time. This situation constrains population to supply with drinking water elsewhere in boreholes other zones. The primacy of access to traditional wells had also been highlighted by the studies by Boone et al. (2011). According to the authors, in rural zones, the wells were the closest water sources to the populations than surface water or public standpipes. In Asia, Sellamuttu et al. (2013) also noted that the average access time varied between 3 and 5 minutes for private wells and 15 to 20 minutes for public wells. In relation to our study, the private wells are those located inside the concessions, at least 5 minutes of walk. Public wells are located more than 5 minutes away. Akoyeyer (2016) also reported that $92.4 \%$ of households take less than 10 minutes to obtain water at unprotected wells (traditional wells) and in average $27 \%$ of households have access to boreholes in Nigeria. According to Mats (2012), 53\% of the population in rural zones had access to unprotected sources water, in other words, traditional wells and surface water.

The fact that households go to boreholes more than traditional wells in Bonogo is explained by the proximity of these water pumps and their number. The surveys reveal that $26 \%$ of families does not collect water from wells and 54\% of them know the wells drying every year. The population of Bonogo have more access to the boreholes due to the proximity of this village to the urban centre of Ouagadougou and benefited from its program of supply in drinking water. This corroborates with the study of Akoteyon (2016), who noticed the relatively high access in three villages in Nigeria is attributed to the proximity to the urban centre.

Our results corroborate those of Béré (2012). Béré indicated that $31 \%$ of the population had access to a drinking water in boreholes that was located within 500 meters of the houses; $42 \%$ of them were situated between 500 meters and 1 kilometer and $27 \%$ more than 1 kilometer to this source of water. In relation with our study, the distance inferior or equal to 500 meters corresponds to a travel time of 5 maximum minutes. Between 500 meters and 1 kilometer of distance corresponds to between 5 and 30 minutes of travel time. Whereas for the distance beyond 1 kilometer the equivalence indicates a travel time of more than 30 minutes.

Elsewhere, the conclusion of the studies conducted by Slaymaker \& Bain (2017) seems to corroborate with our results since these authors estimated that 8 out of 10 households spent more than 30 minutes and sometimes more than one hour on each journey for searching drinking water in sub-Saharan Africa. For Houeha (2007), among the women who collect the drinking water in Benin, $42 \%$ made a return trip at 30 minutes, $46.7 \%$ between 30 and 60 minutes and $11 \%$ beyond 60 minutes. 
The quantities of water collected seem to depend on the distance to the sources. The quantities of water collected is correlated at $r=0.223$ degree with time to access boreholes in Toessin. Whereas this variable is tied at $r=-0.223$ and $r=0.244$ degrees respectively with time to access wells and boreholes in Bonogo. Thus, important quantities of water are collected daily when the time taken to reach the sources does not exceed 30 minutes. Besides, in this study, quantity of water collected is correlated at $r=0.252$ and $r=0.108$ degree respectively with household size for Bonogo and Toessin. The correlation is more statistically significant in Bonogo than Toessin. However, some authors, such as Rosen \& Vincent (1999), have estimated that reducing of the distance to the water source did not increased the quantities of water used per person and by day. According to them, the size of the container used to bring the water at homes determines its use for the household. Also, the fact that some African families prefer to have their children wash and washing clothes at the water sources showed the difference between the quantities of water used and those brought in the house. Elsewhere, Boone et al. (2011), thought that the distance or taken time from dwelling to water source do not affect the choice of water source.

\section{Conclusion}

This study shows that traditional wells and boreholes are the main sources of drinking water in the villages of Toessin and Bonogo, in Burkina Faso. In terms of accessibility, $66 \%$ of households surveyed in Toessin have improved service or intermediate access to drinking water for traditional wells while $18.5 \%$ of them get the same service for boreholes. The households in Toessin collect between collect between 5 and 25 cans of 20 liters per day. For the same quantities of water, $57 \%$ and $41 \%$ of households have a low service or minimal access to these same water sources. There is $7 \%$ of families in state of limited service or no access to water for traditional wells, while no household is in this very state for boreholes.

In the village of Bonogo, surveys have revealed that $22 \%$ and $4 \%$ of households have improved service or intermediate access to boreholes and traditional wells. The whole surveyed households have a low service or minimum access for boreholes while $53 \%$ of families is in this situation for traditional wells. In total, $2 \%$ and $12 \%$ of families are in state of limited service or have no access to boreholes and traditional wells. In terms, traditional wells are more accessible in Toessin, while in Bonogo boreholes are more accessible for the households interviewed. Thus, access to wells/boreholes is correlated significantly with number of wells/boreholes. Number of wells/boreholes is also related significantly with time access to wells/boreholes. The study concluded that, in study sites, access to drinking water is determined by distance separating residence and water sources. Nevertheless, the proximity to urban centre explains the improvement of access to drinking water supply in Bonogo.

Based on the findings, in order to reduce time access to water source, it is necessary to construct dams or to dig new boreholes in Toessin village in view of the increasing density of the population and numbers of district. In order to assure better access and the durability of these hydraulic infrastructures, it would indispensable to set in associations for better management of the facilities.

\section{Acknowledgement}

The authors of the article sincerely thank the Project Livelihood Gotenborg of the International Agency for the Development of Sweden (AIDS) for financing this study and their assistance. 


\section{References}

Akoteyon, I.S. (2016). Pattern of household access to water supply in sub-urban settlements in parts of Lagos State, Nigeria. Geografia-Malaysian Journal of Society and Space, 12(7), 93-106.

Boone, C., Glick, P., \& Sahn, D.E. (2011). Household water supply choice and time allocated to water collection: Evidence from Madagascar. Journal of Development Studies, 47(12), 1826-1850.

Béré, C.A. (2012). Inquiry of users' satisfaction of services and works of AEP put in using of the PN-AEPA in 6 communes in Burkina. Final report. Permanent secretariat of the NGO, Burkina Faso.

Baron, C. \& Bonnassieu, A. (2011). The stakes of the access to water in West Africa: diversity of the modes of governance and conflicts of uses. Mondes en développement, 4(156), 17-32.

Chevallier-Le-Guyader, M.F. (2012). Water and availability: rivalries and risks. Retrieved from https://www.ihest.fr/les-formations/le-cycle-national/

Cusson, F., Corneau, M., \& Cousineau, M.M. 2010. Introductory Guide to SPSS Software, elaborated guide for Students. In CRI-1600 G: Introduction to quantitative methods, Students Users Guide, University of Montréal, Canada.

Demie, G., Bekele, M., \& Seyoum, B. (2016). Water accessibility impact on girl and women's participation in education and other development activities: the case of Wuchale and Jidda Woreda, Ethiopia. Environmental System Research, 5(11), 1-12.

Dione Y. (2014). Participation of the public and political of access to the drinking water in Senegalese rural zone (PhD dissertation). Retrieved from University of Toulouse.

Dos-Santos, S. (2006). Access to water and socio-sanitary stakes in Ouagadougou, Burkina. Espace Populations Sociétés, 2-3, 271-285.

Ho, J.C., Russel, K.C., \& Davis, J. (2014). The challenge of global water access monitoring: evaluating straight-line distance versus self-reported travel time among rural households in Mozambique. Journal of Water and Health, 12(1), 173-183.

Ifabiyi, I.P., Geoffrey, E.O., \& Salami, A.A. (2019). Assessment of water accessibility and quantity in Ilorin south local government area. Geografia-Malaysian Journal of Society and Space, 15(3), 104-121.

Karuaihe, S., Mosimane, A., Nhemachena, C., \& Matundu, O.K. (2014). Rural water access and management approaches in Southern Africa: Lessons from Namibia and South Africa. Journal of Environmental Science and Engineering B, 3, 332-344.

Koolwal G. \& Van de Walle D. (2013). Access to Water, women's work, and child outcomes. Economic Development and Cultural Change, 61(2), 369-405.

Laurence, M. (2004). The water resource in Burkina Faso management and stakes. Travaux du Laboratoire de Géographie Physique Appliquée, 22, 37-55.

Mahmood, S. (2016). What distance is travelled to collect water? Retrieved from http://ecoloodi.org/distance-collecte-eau

Mats, L. (2012). Trends in water availability and accessibility and potential impact on nutrition in Africa. Background document for the sunray project. www.sunrayafrica.co.za

M'body, M. (2009). Decentralization and water resources management: case of Bama commune (Master thesis). Retrieved from International Institute of Engineering of Water and the Environment ( $2 \mathrm{iE})$.

National Institute of the Statistical and Demography (INSD). (2009). Compilation of concepts, definitions, indicatory and used methodology in the national statistical system. Final report. INSD Ouagadougou, Burkina Faso. 
Olanrewaju, R.M., Adedoyin, F. \& Akpan, G.P. (2019). Evaluation of climate variability impact on sources of water supply. Geografia-Malaysian Journal of Society and Space, 15(3), 57-75.

Olivier De Sardan, J.P. \& Elhadji, D.A. (2001). Does the community management serve it the public interest? The case of the hydraulic villager in Niger. Politique Africaine, 80, 153-158.

Ouadba, J.M. (2003). Characterization of the vegetation of the anthropised environments of the Province of Bazega, in Burkina Faso ( $\mathrm{PhD}$ dissertation). Retrieved from University of Ouagadougou.

Ousseini, P. (2010). Access to the drinking water in the peripheral districts of Ouagadougou: case of the sectors 23 and 24 (Master thesis). Retrieved from International Institute of Engineering of Water and the Environment (2iE).

Program Water and Cleaning up. (2011). Water supply and cleaning up in Burkina. Inventory of fixtures proposed by AMCOW. Final report. Ministry of the environment and water, Burkina Faso.

Program GIRE, (2001). Inventory of fixtures water resources in Burkina and their using of management. Final Report. Ministry of the environment and water, Burkina Faso.

Richardson, M.J. (2017). The analysis of water availability indicators and access to available water in the developing, semi-arid, rural setting (Master thesis). Retrieved from University of Illinois at Urbana-Champaign.

Rosen, S., \& Vincent, J.R. (1999). Household water resources and rural productivity in SubSaharan Africa: A review of the evidence. Report paper of Harvard Institute for International Development of USA.

Sellamuttu, S.S., Joffre, O., Suhardiman, D., Balasubramanya, S., Pavelic, P., Htut, U.Y.T., McCartney, M., \& Johnston R. (2013). Community survey on water access, availability and management issues in the dry zone of Myanmar. Final Report for Component 2. Livelihoods and Food Security Trust Fund

Slaymaker, T. \& Bain, R. (2017). Access to drinking water around the world in five infographics. Global Development Professionals Network. Retrieved from www.theguardian.com/ global-development-professionalsnetwork/2017/mar/17/access-to-drinking-water-world-six-infographics.

Traoré, R. (2012). Water, territory and conflicts: Analysis of stakes of the water communal management in Burkina Faso: the example of the basin river of the Nakambé ( $\mathrm{PhD}$ dissertation). Retrieved from University of Toulouse.

UNICEF. (2016). Annual report 2016. Annual Report of the Executive Director of UNICEF presented to the Executive Board, 13-16 June 2017.

UNICEF Media Team. (2016). Collecting water is often colossal waste time for women and girls.

Retrieved from: http://www.unicef.org/press-releases/unicef-collecting-water-often-colossalwaste-time-women-and-girls

WHO \& UNICEF. (2017). Progress on Drinking Water, Sanitation and Hygiene: 2017 Update and SDG Baselines.

Zoungrana, M. (2013). Combined effects of the climate and anthropogenic pressures on the classified forest of Toessin (province of Passoré) (Master thesis). Retrieved from Private Institute of Space Studies and Telecommunications (ISESTEL). 